\title{
Does Dialysis Modality Influence the Oxidative Stress of Uremic Patients?
}

\author{
Cristina Capusa $^{a, c}$ Irina Stoian $^{b}$ Elvira Rus $^{d}$ Dana Lixandru $^{b}$ \\ Carmen Barbulescud ${ }^{d}$ Gabriel Mircescu ${ }^{a, c}$ \\ ${ }^{a}$ Nephrology Department, ${ }^{b}$ Biochemistry Department, 'Carol Davila' University of Medicine and Pharmacy, \\ 'Nephrology, and dDialysis Center, 'Dr Carol Davila' Teaching Hospital of Nephrology, Bucharest, Romania
}

\section{Key Words}

Continuous ambulatory peritoneal dialysis $\cdot$ Hemodialysis •

Extracellular antioxidant status $\cdot$ Oxidative stress $\cdot$ Lipid

peroxidation $\cdot$ Chronic kidney disease

\begin{abstract}
Background/Aims: Since peritoneal membrane is more compatible and residual renal function better preserved during peritoneal dialysis, we questioned whether the oxidative burden in chronic kidney disease (CKD) is influenced by dialysis modality. Methods: 49 stable CKD patients, 17 on continuous ambulatory peritoneal dialysis (CAPD), 16 on hemodialysis (HD), and 16 non-dialyzed, and 13 healthy subjects were enrolled. Plasma thiobarbituric acid-reactive substances (TBARS; nmol/g protein), serum total antioxidant activity (TAA), total plasma-free thiols (Pt-SH; $\mu \mathrm{mol} / \mathrm{g}$ protein), albumin and uric acid were measured by spectrophotometry. Serum residual antioxidant activity (RAA) was calculated. Results: TBARS were higher in HD $(78.3 \pm 20.3)$ versus both non-dialyzed (53.1 $\pm 27.9, \mathrm{p}=0.007)$ and CAPD groups (58.3 $\pm 19.8, p=0.008$ ). Pt-SH was reduced in CKD patients, but showed comparable values between dialysis groups. TAA and RAA were similarly increased in HD and CAPD patients than in the other two groups. Conclusion: Oxidative stress occurs in all CKD patients and worsens as renal function declines. Lipid peroxidation seems more augmented during
\end{abstract}

chronic HD as compared to CAPD, but the plasma antioxidant status did not differ between the investigated dialysis methods. Therefore, dialysis modality appears to influence lipid peroxidation without changing the extracellular antioxidant defense of CKD patients.

Copyright $\odot 2012$ S. Karger AG, Basel

\section{Introduction}

Chronic kidney disease (CKD) was associated with oxidative stress primarily related not only to the uremic state itself, but also to the influence of the dialysis procedure (fig. 1). In patients with declining kidney function, increased levels of protein and lipid oxidation were observed as early as glomerular filtration rate (GFR) was $<20 \mathrm{ml} / \mathrm{min}$ [1]. Chronic inflammation accompanied by increased complement activation, increased cytokines production and neutrophil priming, along with retained uremic solutes which are substrates for oxidative injury, could contribute to the pro-oxidative milieu in uremia [2]. Concomitant impairment of antioxidant defense systems, especially depletion of reduced thiol groups partially related to malnutrition, and decreased activity of antioxidant enzymes were also involved [3].

Dialytic therapy could improve the redox balance by removing oxidized substrates [2]. However, the bioin-

\section{KARGER}

Fax +4161306 1234 E-Mail karger@karger.ch www.karger.com

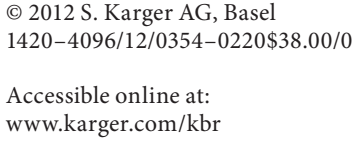

Cristina Capusa, MD, PhD, Assistant Professor

'Carol Davila' University of Medicine and Pharmacy

'Dr Carol Davila' Teaching Hospital of Nephrology

4 Calea Griviței, Sector 1, RO-010731 Bucharest (Romania)

Tel. +40 722409 832, E-Mail ccalexandr@yahoo.com 


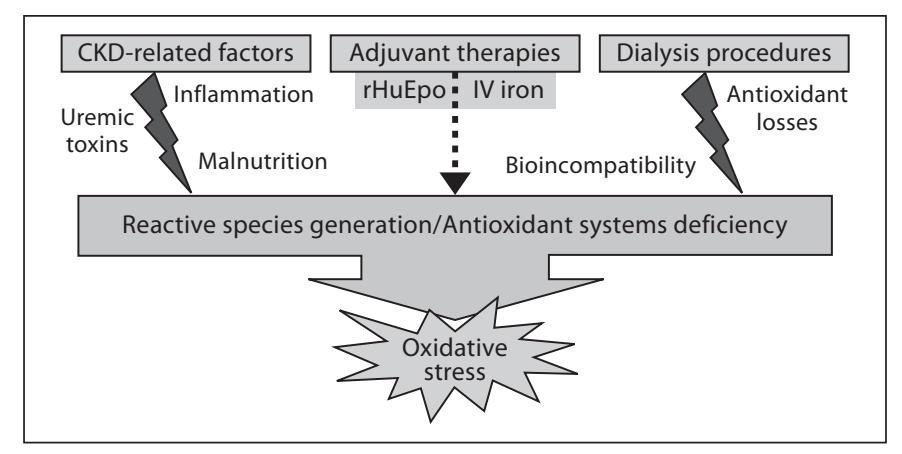

Fig. 1. Multifactorial origin of oxidative stress in chronic dialysis patients. $\mathrm{CKD}=$ Chronic kidney disease; $\mathrm{rHuEpo}=$ recombinant human erythropoietin; IV = intravenous.

compatibility of the dialyzer membranes and bacterial contaminants from dialysate were involved in the augmented production of reactive oxygen species in hemodialyzed patients [1]. Also, the high concentration of glucose, glucose degradation products, low $\mathrm{pH}$ and high osmolality of the dialysis fluid might enhance local and systemic oxidative stress in peritoneal dialysis (PD) [4]. Additionally, accumulating evidence suggest that the major antioxidant systems are impaired in chronic dialysis patients $[5,6]$.

Based on the higher permeability and compatibility of the peritoneal membrane, the avoidance of peaks and troughs in uremic toxins [7] and on the better-preserved residual renal function [8], a lower oxidative burden could be assumed in PD patients. On the other hand, the unfavorable serum lipid profile and the chronic exposure of peritoneal cells to superphysiologic glucose level could increase glycosylation and lipid oxidation in PD patients [7]. So far, the only few studies which directly compared the effects of hemodialysis (HD) and PD on oxidative stress yielded equivocal results [9-13].

The present study investigates the influence of dialysis modality on lipid peroxidation and extracellular antioxidant defense by comparatively assessing some oxidative stress parameters in patients treated by maintenance $\mathrm{HD}$ and continuous ambulatory peritoneal dialysis (CAPD).

\section{Subjects and Methods}

\section{Subjects}

Forty-nine non-diabetic, clinically stable CKD patients and 13 healthy subjects were enrolled in this observational, cross-sectional study. 17 patients with CKD stage 5 were treated by CAPD for at least 9 months (CAPD group). PD was performed by four exchanges daily (three in the daytime and one overnight), with 1.5-2 1/exchange of conventional heat-sterilized PD fluids containing $1.36 \%$ glucose. Median residual diuresis was $500 \mathrm{ml}$ (range $0-1,700 \mathrm{ml}$ ), and median volume of ultrafiltration per day was $1,000 \mathrm{ml}$ (range $300-1,800 \mathrm{ml}$ ). 16 patients on maintenance HD for more than 12 months were included in the HD group. HD protocols consisted of three sessions per week, $4.5 \mathrm{~h}$ per session, with single-used low-flux polysulfone membrane dialyzers $1.3 \mathrm{~m}^{2}$ (in vitro ultrafiltration coefficient $5.5 \mathrm{ml} / \mathrm{h} / \mathrm{mm} \mathrm{Hg}$, either ethylene oxide, F6, or steam sterilized, F6HPS; Fresenius Medical Care, Bad Homburg, Germany), bicarbonate-based dialysate and standard heparinization (mean total dose per session 6,720 $\pm 2,310$ IU). Dialyzed groups were matched for the dialysis vintage.

The non-dialysis CKD group comprised 16 patients with mean estimated GFR (abbreviated MDRD formula [14]) $21.9 \pm 6.8 \mathrm{ml} /$ min, who were not considered candidates for renal replacement therapy in the next 6 months, randomly selected from those attending the Nephrology Clinic over a period of 6 months.

All CKD groups had a similar distribution according to primary renal disease, with primary chronic glomerulonephritis being the main cause of CKD. Neither the prevalence of arterial hypertension $(82 \%$ in CAPD, $69 \%$ in $\mathrm{HD}$, and $75 \%$ in non-dialyzed CKD group, $\mathrm{p}=0.61$ ) nor the cardiovascular diseases burden defined as documented history of stroke, peripheral atherosclerotic disease and/or coronary artery disease (59\% in CAPD, $50 \%$ in $\mathrm{HD}$, and $38 \%$ in non-dialyzed CKD group, $\mathrm{p}=0.09$ ) differed among groups. Chronic drug therapies were comparable in all patients.

Thirteen age- and gender-matched healthy volunteers, with normal routine biochemistry and urinalyses, recruited from the medical and research staff, served as control group. They did not take any medication or nutritive supplements.

Patients with inflammatory and infectious conditions and/or C-reactive protein $>5 \mathrm{mg} / \mathrm{l}$, diabetes mellitus, active chronic liver diseases, malignancies, medications with pro- or antioxidative potentialities (i.e. iron supplementation, non-steroidal anti-inflammatory drugs, captopril, $\mathrm{C}$ and $\mathrm{E}$ vitamins, folic acid, allopurinol, and statins) were excluded. None of the patients received blood transfusions, erythropoietin or intravenous iron therapy at least 2 months preceding the enrollment. Unusual food habits and current active smoking were, also, exclusion criteria. The main characteristics of the investigated subjects are summarized in table 1 .

The study was approved by the local ethical committee. An informed consent was obtained from all participants before any study procedure.

\section{Methods}

Venous blood samples were drawn after overnight fasting, in standard vacuum tubes with heparin (for plasma assays) or without anticoagulant (for serum assays). In HD patients, blood was drawn from the arteriovenous fistula just before the start of the HD session, prior to administration of heparin. Samples were kept on ice, protected from light, and were processed within 30 min of sampling. Plasma and serum were obtained by centrifugation at $3,000 \mathrm{~g}$ for $10 \mathrm{~min}$ at room temperature.

Routine Chemistry

Usual biochemical parameters, including serum uric acid, serum albumin and $\mathrm{C}$-reactive protein were measured by routine 
Table 1. Main characteristics of the subjects

\begin{tabular}{|c|c|c|c|c|}
\hline Parameter & CAPD group & HD group & CKD non-D group & Controls \\
\hline Number & 17 & 16 & 16 & 13 \\
\hline Age, years ${ }^{\mathrm{a}}$ & $53.3 \pm 13.7$ & $49.2 \pm 11.1$ & $52.5 \pm 13.3$ & $48.4 \pm 10.3$ \\
\hline Male/female & $8 / 9$ & $8 / 8$ & $9 / 7$ & $6 / 7$ \\
\hline \multicolumn{5}{|l|}{ CKD etiology, $\mathrm{n}$} \\
\hline Primary glomerulonephritis & 7 & 8 & 6 & - \\
\hline Tubulointerstitial nephropathies & 5 & 4 & 4 & - \\
\hline Vascular nephropathies & 4 & 2 & 3 & - \\
\hline Autosomal dominant polycystic kidney disease & 0 & 2 & 2 & - \\
\hline Other & 1 & 0 & 1 & - \\
\hline \multicolumn{5}{|l|}{ Chronic drug therapies, $\mathrm{n}$} \\
\hline ACEI/ARB & 7 & 4 & 4 & - \\
\hline$\beta$-Blockers & 2 & 1 & 5 & - \\
\hline Calcium channel blockers & 5 & 5 & 5 & - \\
\hline Other antihypertensives & 1 & 3 & 4 & - \\
\hline Antiplatelet drugs & 2 & 5 & 2 & - \\
\hline Nitrate drugs & 6 & 3 & 7 & - \\
\hline Diuresis, $1 /$ day $^{\mathrm{b}}$ & $0.5[0.2-0.9]^{\mathrm{c}-\mathrm{e}}$ & $0.13[0.02-0.5]^{\mathrm{d}, \mathrm{e}}$ & $1.5[1.5-1.9]$ & $1.5[1.4-1.7]$ \\
\hline Body mass index, $\mathrm{kg} / \mathrm{m}^{2 \mathrm{a}}$ & $25.4 \pm 2.9^{\mathrm{d}}$ & $23.7 \pm 4.0$ & $22.8 \pm 3.1^{\mathrm{e}}$ & $25.3 \pm 2.6$ \\
\hline Systolic blood pressure ${ }^{b}$ & $140[130-170]$ & $140[130-156]$ & $150[138-173]^{\mathrm{c}, \mathrm{e}}$ & $135[120-140]$ \\
\hline Diastolic blood pressure ${ }^{b}$ & $80[70-90]$ & $80[78-81]$ & $85[78-100]$ & $80[70-80]$ \\
\hline Serum ferritin, $\mu \mathrm{g} / \mathrm{l}^{\mathrm{b}}$ & $150[90-351]$ & $278[137-483]$ & $201[80-294]$ & $121[101-348]$ \\
\hline Serum C-reactive protein, $\mathrm{mg} / \mathrm{l}^{\mathrm{a}}$ & $3.9 \pm 1.0$ & $3.3 \pm 1.1$ & $3.1 \pm 0.9$ & $2.9 \pm 0.8$ \\
\hline Serum cholesterol, $\mathrm{mmol} / \mathrm{l}^{\mathrm{a}}$ & $5.72 \pm 1.06$ & $5.28 \pm 0.9$ & $5.25 \pm 1.1$ & $5.80 \pm 0.63$ \\
\hline Serum triglycerides, $\mathrm{mmol} / \mathrm{l}^{\mathrm{a}}$ & $1.75 \pm 0.7$ & $1.66 \pm 0.44$ & $1.59 \pm 0.64$ & $1.48 \pm 0.65$ \\
\hline Serum hemoglobin, $g / 1^{\mathrm{a}}$ & $98 \pm 22^{\mathrm{e}}$ & $99 \pm 16^{\mathrm{e}}$ & $100 \pm 27^{e}$ & $141 \pm 13$ \\
\hline Serum creatinine, $\mu \mathrm{mol} / \mathrm{l}^{\mathrm{a}}$ & $778 \pm 115^{\mathrm{c}-\mathrm{e}}$ & $654 \pm 88^{\mathrm{d}, \mathrm{e}}$ & $371 \pm 168^{\mathrm{e}}$ & $80 \pm 9$ \\
\hline
\end{tabular}

$\mathrm{CAPD}=$ Continuous ambulatory peritoneal dialysis; $\mathrm{HD}=$ hemodialysis; $\mathrm{CKD}=$ chronic kidney disease; non- $\mathrm{D}=$ non-dialyzed; $\mathrm{ACEI}=$ angiotensin-converting enzyme inhibitors; $\mathrm{ARB}=$ angiotensin receptor blockers.

${ }^{\mathrm{a}}$ Mean $\pm \mathrm{SD} ;{ }^{\mathrm{b}}$ median [interquartile range], $\mathrm{p}<0.05:{ }^{\mathrm{c}}$ versus HD group; ${ }^{\mathrm{d}}$ versus CKD non-D group; ${ }^{\mathrm{e}}$ versus controls.

enzymatic methods using the multiparameter analyzer Falcor 300 (Menarini Diagnostics, Florence, Italy). Hemoglobin concentrations were determined by spectrophotometry $(\lambda=525 \mathrm{~nm}$; Coulter AcT Diff ${ }^{\mathrm{TM}}$; Beckman Coulter, Miami, Fla., USA).

Oxidative Stress Parameters

Following centrifugation, the plasma and serum aliquots were stored at $-70^{\circ} \mathrm{C}$ until use. Reagents of pure analytical quality, purchased from Sigma-Aldrich Chemie (Steinheim, Germany), and ultrapure water were treated with Chelex 100 (Merck, Darmstadt, Germany) in order to bind transitional metals. All assays were performed by spectrophotometry on a Perkin-Elmer Lambda EZ 210 (Perkin-Elmer Inc., Boston, Mass., USA) and were carried out on triplicate samples.

Plasma thiobarbituric acid-reactive substances (TBARS), the most prevalent substrate of which is malondialdehyde (MDA), as marker of lipid peroxidation, were determined according to Esterbauer and Cheeseman [15]. To prevent artifactual oxidation during the assay procedure, plasma aliquots were treated with butylated hydroxytoluene and then mixed with $0.67 \%$ thiobarbituric acid (TBA) and 20\% trichloroacetic acid. Blank samples from dis- tilled water and the same reagents were prepared. The reaction mixture was heated for $1 \mathrm{~h}$ at $100^{\circ} \mathrm{C}$ and then cooled with tap water. The pink TBA-reacting substances adduct was extracted in $n$-butanol. After centrifugation, the absorbance of the organic layer was read at $532 \mathrm{~nm}$. The results were calculated as MDA equivalents using the extinction coefficient for the MDA-TBA complex of $153,000 \mathrm{M}^{-1} \mathrm{~cm}^{-1}$, and were expressed as $\mathrm{nmol} / \mathrm{g}$ protein.

Plasma total-free thiols (Pt-SH) were assayed according to the Ellman method [16]. Briefly, aliquots of plasma were mixed with $5 \mathrm{~mm}$ phosphate buffer $(\mathrm{pH}=8)$ and $10 \%$ sodium dodecyl sulfate. Then, Ellman's reagent was added and samples were incubated at $37^{\circ} \mathrm{C}$ for $1 \mathrm{~h}$. The absorbance was read at $412 \mathrm{~nm}$ against a reagent blank. Results were calculated using a calibration curve with glutathione as standard, and expressed as $\mu \mathrm{mol} / \mathrm{g}$ protein.

Serum total antioxidant activity (TAA) was measured as the relative abilities of antioxidants to scavenge the 2,2'-azino-bis(3ethylbenzothiazoline-6-sulfonic acid) (ABTS) radical cation in comparison with the antioxidant potency of standard amounts of Trolox, the water-soluble vitamin E analogue [17]. A solution of ABTS radical, which was obtained from the light-protected ABTS reaction with potassium persulfate, was added to the serum sam- 
Table 2. Oxidative stress parameters in studied groups

\begin{tabular}{|c|c|c|c|c|}
\hline Parameter & CAPD group & HD group & CKD non-D group & Controls \\
\hline TBARS, nmol/g protein ${ }^{\mathrm{a}}$ & $58.3 \pm 19.8^{\mathrm{c}, \mathrm{e}}$ & $78.3 \pm 20.3^{\mathrm{d}, \mathrm{e}}$ & $53.1 \pm 27.9$ & $42.0 \pm 13.0$ \\
\hline $\mathrm{Pt}-\mathrm{SH}, \mu \mathrm{mol} / \mathrm{g}$ protein $^{\mathrm{a}}$ & $6.1 \pm 0.8^{\mathrm{e}}$ & $6.3 \pm 0.9^{\mathrm{e}}$ & $6.1 \pm 1.0^{\mathrm{e}}$ & $7.3 \pm 0.8$ \\
\hline Serum TAA, mmol/ $\mathrm{l}^{\mathrm{a}}$ & $1.3 \pm 0.1^{\mathrm{d}, \mathrm{e}}$ & $1.2 \pm 0.1^{\mathrm{d}, \mathrm{e}}$ & $1.0 \pm 0.1$ & $0.9 \pm 0.2$ \\
\hline Serum RAA, mmol/ $\mathrm{l}^{\mathrm{b}}$ & $0.5[0.45-0.6]^{\mathrm{d}, \mathrm{e}}$ & $0.4[0.38-0.58]^{\mathrm{d}, \mathrm{e}}$ & $0.2[0.05-0.36]$ & $0.2[0.05-0.35]$ \\
\hline Serum albumin, $\mathrm{g} / \mathrm{l}^{\mathrm{a}}$ & $37 \pm 4^{\mathrm{e}}$ & $39 \pm 3^{\mathrm{e}}$ & $39 \pm 6^{\mathrm{e}}$ & $46 \pm 3$ \\
\hline Serum uric acid, $\mu \mathrm{mol} / \mathrm{l}^{\mathrm{a}}$ & $363 \pm 48^{\mathrm{e}}$ & $363 \pm 101^{\mathrm{e}}$ & $404 \pm 89^{e}$ & $280 \pm 89$ \\
\hline
\end{tabular}

$\mathrm{CKD}=$ Chronic kidney disease CAPD = continuous ambulatory peritoneal dialysis; $\mathrm{HD}=$ hemodialysis; non-D = non-dialyzed; TBARS = plasma thiobarbituric acid reactive species; $\mathrm{Pt}-\mathrm{SH}=$ plasma total free thiols; $\mathrm{TAA}=$ total antioxidant activity; $\mathrm{RAA}=$ residual antioxidant activity.

${ }^{\mathrm{a}}$ Mean $\pm \mathrm{SD} ;{ }^{\mathrm{b}}$ median [interquartile range], $\mathrm{p}<0.05:{ }^{\mathrm{c}}$ versus HD group; ${ }^{\mathrm{d}}$ versus CKD non-D group; ${ }^{\mathrm{e}}$ versus controls.

ple until a concentration of $150 \mu \mathrm{mol} / \mathrm{l}$. The absorbance was read after $1 \mathrm{~min}$ at $734 \mathrm{~nm}$ against a reagent blank (prepared with $5 \mathrm{~mm}$ phosphate buffer treated as the sample). The percentage inhibition of the absorbance, which is directly proportional to the antioxidant activity of the sample, was calculated. The assay was calibrated against a calibration curve with Trolox as standard, and the results were expressed as mmol/l Trolox activity.

Serum residual antioxidant activity (RAA) was calculated by subtracting the TAA activity ascribable to serum albumin and uric acid from the TAA value, according to the formula [18]:

RAA $(\mathrm{mm} / \mathrm{l})=$ TAA $(\mathrm{mm} / \mathrm{l})-[($ serum albumin $\mathrm{mM} / \mathrm{l} \times 0.69)$ $+($ uric acid $\mathrm{mm} / \mathrm{l} \times 1)]$

Statistical Analysis

Data were reported as mean $\pm \mathrm{SD}$ or median and interquartile range, and were compared using analysis of variance (ANOVA) or Kruskal-Wallis test for parametric and non-parametric variables, respectively. Bartlett's test was used to assess the homogeneity of variance between groups. Correlations between parameters were tested by linear regression analysis. A p value $<0.05$ was considered significant.

\section{Results}

There were no significant differences among groups regarding age, gender, serum ferritin or lipids status (table 1). Dialysis vintage was similar in CAPD and HD groups (39 (range 13-110) versus 58 (19-110) months $(\mathrm{p}=0.20))$, and no differences in urea Kt/V existed $(1.3$ \pm 0.1 in CAPD subjects and $1.5 \pm 0.2$ in HD group, $p=$ 0.61 . The CAPD group had a higher body mass index than non-dialyzed subjects, but similar to HD patients. Only serum creatinine and residual diuresis were significantly higher in PD than in HD patients (table 1). Both dialyzed groups had lower residual diuresis than non-dialyzed CKD and control subjects. Similar propor- tions of anuric patients (i.e. daily urinary output $<300$ $\mathrm{ml}$ ) was seen in HD (62\%) and CAPD (36\%) groups ( $\mathrm{p}=$ $0.12)$.

All CKD patients, dialyzed or not, had lower serum albumin and increased serum uric acid concentrations than controls without differences among CKD groups. Although the TBARS levels were higher in both dialysis groups but not in the non-dialysis CKD group than in controls, the highest levels were found in HD patients. A significant increase in TBARS concentration was noticed in this latter group as compared to both non-dialysis and PD subjects. Pt-SH were reduced in CKD patients versus controls, but had comparable values in HD and CAPD groups. Serum total and residual antioxidant activities were enhanced in dialysis patients as compared to the other two groups, but without differences between $\mathrm{HD}$ and CADP patients (table 2).

In CKD non-dialyzed patients, estimated GFR was not correlated with plasma TBARS $(\mathrm{r}=0.223 ; \mathrm{p}=0.41)$, free thiols $(\mathrm{r}=0.444 ; \mathrm{p}=0.09)$ or TAA $(\mathrm{r}=-0.299 ; \mathrm{p}=0.28)$. In dialysis groups, oxidative stress parameters were similar in patients with or without diuresis.

\section{Discussion}

In the present study, enhanced plasma lipid peroxidation was significant only in dialysis patients as compared to controls, indicating a progressive worsening of oxidative stress as kidney function declines and increased conditions for lipid peroxidation in end-stage renal disease patients. Although the oxidative stress was more pronounced in HD patients, the extracellular antioxidant defense parameters were similarly changed irrespective 
of dialysis modality, suggesting a lower oxidative burden in CAPD patients.

While the presence of oxidative stress in ESRD patients is widely accepted $[2,3,5,19,20]$, debate still exists about the differences in lipid peroxidation and antioxidant status between HD and PD. Increased carbonylation of albumin as compared to healthy subjects was found in advanced CKD and HD, but not PD patients [9] and higher carbonyl content of plasma proteins was reported in $\mathrm{HD}$ than in PD patients [10], suggesting less protein oxidative stress associated with PD. Another study described enhanced susceptibility of erythrocytes from CKD and HD but not CAPD patients to in vitro lipid peroxidation in comparison with controls [13]. In accord with our results, these data point to a more favorable profile of $\mathrm{PD}$ regarding carbonyl and oxidative stress. Some reasons could be: (1) the greater bioincompatibility of HD procedure which stimulates the release of reactive oxygen species [1], and (2) a better preserved native kidney function during $\mathrm{PD}[8]$.

However, not all studies had concordant results. For instance, Yonova et al. [11] reported no difference between serum levels of lipid peroxidation markers in $\mathrm{HD}$ and CAPD groups, whereas higher plasma MDA was detected in CAPD than in HD patients [12]. Furthermore, these authors questioned the alleged lesser oxidative burden imposed by PD, as HD and PD patients had similar impairment in erythrocytes and blood glutathione status $[12,21]$.

In the present study, CKD patients on maintenance HD seemed more prone to augmented reactive species generation than those on CAPD, as higher TBARS levels than in non-dialysis CKD patients were observed only in the HD group. Furthermore, when compared to PD patients, the HD group showed notably increased plasma MDA. These findings sustain the enhanced lipid peroxidation associated with chronic HD.

The preservation of the residual kidney function is an important feature in PD patients which could explain their reduced oxidative burden [8]. In our data, although the proportion of anuric patients was similar in both groups, the residual diuresis was higher in PD patients, but diuresis and plasma lipid peroxidation markers were not correlated. Moreover, we could find no correlation between MDA and estimated GFR in non-dialysis CKD patients. However, it is still reasonable to speculate on the beneficial impact of residual renal function on oxidative stress in PD as TBARS was spectrophotometricaly assessed in our study, a method which does not specifically measure MDA.
Published direct comparisons between HD and PD effects on antioxidants are rather scarce and contradictory. While some reported no differences in glutathione systems [12, 21], antioxidant enzymes [22] and serum total antioxidant capacity [23], others found serum antioxidant capacity to be preserved in PD but depleted in HD and hemodiafiltration [24]. In our study, comparable plasma levels of total free thiols, serum total and residual antioxidant activities were observed in both dialyzed group. Hence, dialysis modality seems to exert little influence on non-enzymatic extracellular antioxidant status. The lower concentration of Pt-SH observed in our CKD patients, dialyzed or not, further sustains the oxidative stress associated with CKD.

In line with other studies $[25,26]$, serum TAA was higher in dialysis patients than in controls. Since uric acid is the second most significant serum antioxidant in terms of mass and activity [16], hyperuricemia frequently encountered in CKD patients could account for the mentioned finding. However, because our dialysis groups had higher TAA than non-dialysis subjects, despite similar serum uric acid values, other explanations could be suggested. Firstly, plasma antioxidant capacity might reveal a response to an augmented oxidative stress, which is not necessarily a desirable change [27]. Moreover, the in vitro assay could detect the antioxidant activity of certain substances without such activity in vivo, thus overestimating the in vivo reality [28].

In conclusion, our data suggest the occurrence of oxidative stress in all CKD patients (as sustained by the plasma thiol consumption), and its worsening as the renal function declines since it was augmented in patients on renal replacement therapy (as indicated by the increased lipid peroxidation). The greater enhancement of TBARS concomitant with the lack of differences among antioxidant parameters found between studied HD and CAPD patients indicate that dialysis modality influences plasma lipid peroxidation without changing the extracellular antioxidant defense of CKD patients. Conventional chronic HD seems associated with enhanced oxidative stress as compared to PD. Furthermore, it could be speculated that augmented generation of reactive species due to increased bioincompatibility of dialysis procedure rather than plasma antioxidant deficiencies is the main contributor to the observed difference.

\section{Disclosure Statement}

The authors have no conflicts of interest to disclose. 


\section{References}

1 Ward RA, McLeish KR: Oxidant stress in hemodialysis patients: What are the determining factors? Artif Organs 2003;27:230-236.

$\checkmark 2$ Himmelfarb J, Stenvinkel P, Ikizler TA, Hakim RM: The elephant in uremia: oxidant stress as a unifying concept of cardiovascular disease in uremia. Kidney Int 2002;62: 1524-1538.

3 Ceballos-Picot I, Witko-Sarsat V, MeradBoudia M, Nguyen AT, Thévenin M, Jaudon MC, et al: Glutathione antioxidant system as a marker of oxidative stress in chronic renal failure. Free Radic Biol Med 1996;21:845853.

$\checkmark 4$ Agalou S, Ahmed N, Dawnay A, Thornalley PJ: Removal of advanced glycation end products in clinical renal failure by peritoneal dialysis and haemodialysis. Biochem Soc Trans 2003;31:1394-1396.

$\checkmark 5$ Canaud B, Cristol J-P, Morena M, LerayMoragues H, Bosc J-Y, Vaussenat F: Imbalance of oxidants and antioxidants in haemodialysis patients. Blood Purif 1999;17:99106.

-6 Tarng DC, Chen TW, Huang T-P, Chen C-L, Liu T-Y, Wei YH: Increased oxidative damage to peripheral blood leukocyte DNA in chronic peritoneal dialysis patients. J Am Soc Nephrol 2002;13:1321-1330.

7 Ganesh SK, Hulbert-Shearon T, Port FK, Eagle K, Stack AG: Mortality differences by dialysis modality among incident ESRD patients with and without coronary artery disease. J Am Soc Nephrol 2003;14:415-424.

$>8$ Ignace S, Fouque D, Arkouche W, Steghens J-P, Guebre-Egziabher F: Preserved residual renal function is associated with lower oxidative stress in peritoneal dialysis patients. Nephrol Dial Transplant 2009;24:16851689.

9 Mitrogianni Z, Barbouti A, Galaris D, Siamopoulos KC: Oxidative modification of albumin in predialysis, hemodialysis, and peritoneal dialysis patients. Nephron Clin Pract 2009;113:c234-c240.
$>10$

0 Donate T, Herreros A, Martinez E, Martinez J, Andrés E, Cabezas A, et al: Protein oxidative stress in dialysis patients. Adv Perit Dial 2002;18:15-17.

11 Yonova D, Trendafilov I, Papazov V, Stanchev I, Zidarov R, Antonov S: Comparative study of oxidative stress in peritoneal dialysis and hemodialysis patients. Hippokratia 2004;8: 170-172.

12 Ozden M, Maral H, Akaydın D, Cetınalp P, Kalender B: Erythrocyte glutathione peroxidase activity, plasma malondialdehyde and erythrocyte glutathione levels in hemodialysis and CAPD patients. Clin Biochem 2002. 35:269-273.

13 Lucchi L, Bergamini S, Iannone A, Perrone S, Stipo LF, et al: Erythrocyte susceptibility to oxidative stress in chronic renal failure patients under different substitutive treatments. Artif Org 2005;29:67-72.

14 Covic A, Mircescu G, Gluhovschi G, Schiller A, Capusa C, Gusbeth-Tatomir P, et al, for the Romanian Society of Nephrology: Medical Practice Guidelines - Chronic Kidney Disease. Bucharest, Curtea Veche Publishing, 2007, p 19.

15 Esterbauer H, Cheeseman KH: Determination of aldehydic lipid peroxidation products: malondialdehyde and 4-hydroxynonenal. Methods Enzymol 1990;186:407-413.

16 Rice-Evans CA, Diplock AT, Symons MCR: Techniques in Free Radicals Research. Amsterdam, Elsevier, 1991, pp 207-234.

17 Miller NJ, Rice-Evans CA, Davies MJ, Gopinathan V, Milner A: A novel method for measuring antioxidant capacity and its application to monitoring the antioxidant status in premature neonates. Clin Sci 1993;84: 407-412.

18 Miller NJ, Johnston JD, Collis CS, Rice-Evans CA: Serum total antioxidant activity after myocardial infarction. Ann Clin Biochem 1997;34:85-90.

19 Descamps-Latscha B, Drüeke T, Witko-Sarsat V: Dialysis-induced oxidative stress: biological aspects, clinical consequences, and therapy. Semin Dial 2001;14:193-199.
20 Clermont G, Lecour S, Lahet J-J, Siohan P, Vergely C, Chevet D, et al: Alteration in plasma antioxidant capacities in chronic renal failure and hemodialysis patients: a possible explanation for the increased cardiovascular risk in these patients. Cardiovasc Res 2000; 47:618-623.

21 Ross EA, Koo LC, Moberly JB: Low whole blood and erythrocyte levels of glutathione in hemodialysis and peritoneal dialysis patients. Am J Kidney Dis 1997;30:489-494.

22 Mekki K, Taleb W, Bouzidi N, Kaddous A, Bouchenak M: Effect of hemodialysis and peritoneal dialysis on redox status in chronic renal failure patients: a comparative study. Lipids Health Dis 2010;9:93.

23 Samouilidou EC, Grapsa EJ, Kakavas I, Lagouranis A, Agrogiannis B: Oxidative stress markers and C-reactive protein in end-stage renal failure patients on dialysis. Int Urol Nephrol 2003;35:393-397.

24 Rysz J, Stolarek RA, Pedzik A, Nowicki M, Nowak D: Serum antioxidant capacity is preserved in peritoneal dialysis contrary to its robust depletion after hemodialysis and hemodiafiltration sessions. Ther Apher Dial 2010;14:209-217.

25 Kim SB, Yang WS, Min WK, Lee SK, Park JS: Reduced oxidative stress in hypoalbuminemic CAPD patients. Perit Dial Int 2000;20: 290-294.

26 Ahmadpoor P, Eftekhar E, Nourooz-Zadeh J, Servat H, Makhdoomi K, Ghafari A: Glutathione, glutathione-related enzymes, and total antioxidant capacity in patients on maintenance dialysis. Iran J Kidney Dis 2009;3:22-27.

27 Prior RL, Cao G: In vivo total antioxidant capacity: comparison of different analytical methods. Free Radic Biol Med 1999;27:11731181.

28 Nguyen-Khoa T, Massy ZA, Witko-Sarsat V, Thévenin M, Touam M, Lambrey G, et al: Critical evaluation of plasma and LDL oxidant-trapping potential in hemodialysis patients. Kidney Int 1999;56:747-775. 